The travelling citizen: emergent discourses of moral mobility in a study of cycling in London

Judith Green

London School of Hygiene and Tropical Medicine

Rebecca Steinbach

London School of Hygiene and Tropical Medicine

Jessica Datta

London School of Hygiene and Tropical Medicine 


\begin{abstract}
Drawing on accounts of travelling within London, this paper explores the ways in which mobility discourses are tied to the responsibilities of 'a good citizen' and suggests that cardominated automobility has been significantly fractured, at least in one urban setting. A consensus hierarchy of transport modes now configures driving as immoral, as well as dysfunctional, and cycling, in contrast, as particularly laudable. Within this new moral economy of transport, cycling holds the promise of conscientious automobility, enabling a number of explicit and implied citizenship responsibilities to be met. These include ecological responsibilities to the city and global ecosystem, but also responsibilities to enact the "new citizen': a knowledgeable and alert risk-assessor competent to travel in ways that maximise independence, efficiency and health. However, cycling has its own contradictions: whilst enabling some to enact a new 'moral' citizenship, it simultaneously underlines the marginal citizenship of less mobile Londoners.
\end{abstract}

Key words: citizenship, city, cycling, mobility, morality 


\section{The travelling citizen: emergent discourses of moral mobility in a study of cycling in}

London

\section{Introduction: citizenship and mobility}

Making sense of what citizenship means in late modern society entails taking mobility seriously. At the macro level, citizenship has to be reconceptualised for a hyper-mobile world. If traditional analyses of citizenship were oriented to the social, political and civil rights that accrue from membership of a nation state (Marshall 1950), more recent critiques have focused on postnationalism, and the rights and obligations that emerge in the increasingly supranational forms of governance in global societies (Roche 1995, Nash 2009). Urry links the sociology of mobility to contemporary ideas of citizenship in outlining the proliferation of 'citizenships of flow' (Urry 2007: 189) in highly mobile global society, in which the 'rights' of citizenship become associated not with territorial states, but with the 'rights' of agents as consumers, migrants, tourists or visitors, as people travel both physically and virtually across traditional state borders. Hypermobility is thus one element of the 'new citizenship', with the globalization of labour, capital and consumption eroding any straightforward identification of individuals with single geographical territories.

However, co-existing with these globalising tendencies, late modern citizenship also incorporates localism (Turner 1990), and the idea of an 'active' citizen, who is an engaged actor at the microlevel. This 'active citizen' has obligations as well as rights, perhaps most explicitly evident in the growth of participatory democratic institutions in countries such as the United Kingdom (UK) (Marinetto 2003; Martin 2008), which require the citizen to participate in various structures of governance. Isin (2009) further delineates a new figure of citizenship, the 'activist citizen', engaged in struggles over rights in sites as local as the city streets or internet message boards, as well as globally, across international borders. For Isin, what distinguishes 'activist' from 'active' citizenship is that it is enacted: the active citizen is the already-existing citizen, with rights assumed, whereas the activist citizen may have the 'right to claim rights', but is engaged in struggle over their relation to the body politic. Citizenship is thus a process of negotiation and enactment, rather than a state. In this paper we are particularly interested in the more implicit 3 
ways in which forms of citizenship are claimed and evoked in everyday practices of local mobility. In terms of transport, our topic of interest, the new citizen is no passive passenger, but an active agent in a number of overt ways. The 'active citizen' participates in local consultation around traffic calming, and the 'activist' citizen in campaigns against aircraft runways or for more accessibility on public transport. However, the 'new' citizen is also more tacitly evoked in the range of mundane obligations of the competent traveller, a process which Beckman (2001) has called 'reflexive automobilisation'. Taking road safety as an example, Beckman suggests responsibilities are no longer just those of professional safety experts: we are all engaged in reflecting on, managing and changing the risks and possibilities of travel to avoid injury (Beckman 2004). This kind of reflexive citizenship, enacted in the routine ways in which 'proper' behaviour becomes habituated, constitutes the modern citizen as an agential, prudent risk assessor (Nettleton 1997, Higgs 1998). We suggest here that this approach could usefully be extended to other areas of mobility, with the most mundane of transport choices (to cycle or use the bus, for instance) being arenas in which the rights and moral obligations of the contemporary citizen traveller are played out in more or less explicit ways.

Individual transport mode decisions take on a particular significance for citizenship within the context of what has been described as a 'regime of automobility', in which the car dominates, coming to define and structure modernity (Sheller and Urry 2000, Böhm et al 2006, Urry 2007). Sheller and Urry (2000) summarise the 'system' of automobility as characterised by features which produce a taken-for-granted, stabilised set of truths about the car: that it is: the essential, iconic manufactured object, produced by iconic firms; an unquestioned major item of household expenditure; the fulcrum of a complex system of production and supply; the dominant form of quasi-private mobility, which subordinates all others; and, culturally, somehow definitional of the 'good life'. The dysfunctions of such automobility are increasingly acknowledged: the inevitable traffic congestion as car use becomes normalised; environmental effects, such as pollution and the erosion of urban space; the health effects, both directly from transport deaths and injuries, and indirectly from rising obesity risks as physical activity declines; and social effects, from the marginalisation of non-drivers: children, the poor, the physically impaired (Freund and Martin 2004). Böhm and colleagues (2006) suggest that beyond these dysfunctions automobility has inherent contradictions. In its own terms, they argue, it is impossible: 
autonomy and mobility are incompatible because mobility entails ever more complex systems of roads, technologies, laws, enforcement and so on that enable driving. The autonomous subject (symbolized in adverts of a shiny car speeding along empty mountain roads) cannot exist without vast technological networks that make possible both the machine itself, and the hybrid 'personmachine' of the car driver, whose subjectivity is disciplined such that they can tacitly utilize the technology around them, interacting appropriately with those complex networks of other actors, both human and non-human, that constitute transport systems.

\section{Cycling as resistant mobility?}

The dysfunctions and contradictions of car dominated automobility give rise to alternative practices and discourses of mobility. Sociological interest in these alternative and resistant mobilities has included an emergent sociology of modes such as cycling and walking (Fincham 2006, Horton et al 2007, McBeth 2009, Green 2009). In one of the few studies that has linked transport and citizenship, Aldred (2010), drawing on data from Cambridge, where cycling rates are relatively high, has suggested that the 'cycling citizen' explicitly constructs the bicycle in contrast to the car. For Cambridge cyclists, argues Aldred, cycling provides a way of enacting four 'dimensions of citizenship': the environmental citizen, the self-caring citizen, the locally rooted citizen and the citizen in the community. These practices were not necessarily framed as resistant to automobility, in that most cyclists also owned and used cars, but they did offer, Aldred suggests, a potential alternative to the view from 'inside the car'.

Against a backdrop of hegemonic automobility, such alternative mobility practices have generally been framed as merely marginal resistance. Urry (2007: 132), for example, suggests 'living without a car has become a significant lifestyle choice for both environmentalists and a small cosmopolitan elite able to live in expensively gentrified city-centres'. Automobility, it is argued, has always had its discontents, and anti-car movements (Böhm et al 2006), which have not, as yet, dismantled the regime. But Urry and others have speculated on how current political, climate, and other shifts may prove a larger threat. Contemporary policy, arguably, does suggest a challenge to the regime that is more than marginal, in the context of a growing political consensus that oil dependent transport systems are unsustainable. In the United Kingdom (UK), the Department for Transport has ambitious aims for non-car transport, noting that 'cycling helps 
tackle pollution caused by motor vehicles, congestion and also promotes good health' (Department for Transport 2007) and that more cycling and walking will improve social cohesion and reduce global warming (Department for Transport 2004). Both national and regional strategies aim to shift travellers from the car to alternative modes, with Transport for London (the body responsible for delivering the Mayor of London's transport strategy) committed to large increases in cycling in the capital (Transport for London 2004, Mayor of London 2010). Although the impact and coherence of such policy commitment is controversial ${ }^{\mathrm{i}}$, with little evidence of large increases in cycling trips outside the Cycling Demonstration towns ${ }^{\text {ii }}$, it does perhaps illustrate a more mainstream acceptance of alternatives to car-based mobilities, and raises a question of what effect, if any, this has had on public discourses of mobility.

As a setting for examining this question, London provides perhaps an extreme 'deviant case'. With lower than national average levels of car ownership (Department for Transport 2010), a well-developed public transport infrastructure and, importantly for this study, explicit policies aiming to reduce private car use (for instance a congestion charge for cars entering a central zone since 2003), Londoners have perhaps more incentives than others in the UK to adopt 'resistant' mobility practices. However, despite policy commitments to cycling (Mayor of London 2010), rates remain low, at around two percent of all trips, which is in line with the UK nationally and indeed the majority of high income cities outside a few 'cycle friendly' countries of northern Europe (Pucher and Buehler 2008). Our study does not, then, claim to explore a typical site of urban mobility, but rather to reflect on one in which we might expect alternative discourses to be more evident, and thus more researchable, than in other settings.

\section{Methodology}

Drawing on data from a study on transport choices in London (Steinbach et al 2011), this paper explores the relationship of citizenship to local mobility, through a focus on accounts of cycling. The data were generated in 2009, and included: 78 individual interviews and one focus group with people who lived or worked in one of three London boroughs ${ }^{\text {iii }}$, informal conversations with commuters; fieldwork travel diaries kept by the research team; and public textual data including websites. Those formally interviewed were purposively selected to include a range of people 
from the diverse population groups in London likely to be using different travel modes. They were recruited through approaches to private and public sector workplaces, a voluntary organisation and cycle training schemes and included: 42 'cyclists' (defined as those cycling to work at least some days); 24 'non-cyclists' (those who did not cycle for transport); 12 'trainees' recruited from cycle training courses; plus 8 'non-cyclists' in a focus group. The 'trainees' ranged from those learning to cycle to competent cyclists wanting to improve their confidence. This paper draws largely on the formal interview data. Interview extracts are annotated with a pseudonym, and (where available) age range and an indicator of ethnicity. As self-reported ethnic identities were often very specific, and some sampled workplaces small, this indicator is an aggregate grouping ('Black', 'White', 'Asian' 'Mixed' or 'Other') to provide some context without breaching confidentiality, although we are aware that such summaries may not reflect salient aspects of identity for the participants.

Participants were asked to take part in a study on 'Transport choices in London', with interviews covering their routine journeys and experiences of all types of travel in the city. However, our information sheet specified our interest in cycling, and we deliberately over-recruited cyclists. To provide some reflexivity on the potential shaping of our data by assumptions that we were 'procycling', we also kept diaries of our own travel (using a range of modes), taking notes of informal discussions with commuters, and carefully considered accounts generated by different members of the research team (which included both cyclists and non-cyclists) in different contexts. Across the data set, we were struck by the frequency of references to responsibilities and the moral significance of transport choices. This paper explores the implications of these for understanding emergent regimes of mobility in this city, and how these relate to notions of citizenship. Interview and other data were analysed using a thematic content analysis that drew on elements of a grounded theory approach, including detailed open coding, constant comparison (within and across the data sets) and a close attention to deviant cases in the context of analytical ideas from social theory on mobility and citizenship.

\section{Cycling as the new automobility}


In his ethnography of bicycle couriers, Ben Fincham (2006) discusses their demonization as 'bicycle guerrillas' and 'lycra louts' as a function of their very visible subversion of 'the “normalised” world of the motor-car' (2006:217). With (apparently) 'true automobility', the couriers are unencumbered by the antagonisms of car-based automobility, riding when, where and how they want, and engaged in a reflexive romanticisation of their role as urban freedom seekers, daily dicing with death. For Fincham, this is partly a glamorization of what is actually a dangerous and poorly paid occupation, for which aggression and rule breaking are in fact prerequisites for safety. He concludes: cycling is not a 'project to end automobility but rather the reverse, an attempt to reconstitute the principal object or technology through which it is to be understood' (p221), because of course cycling has its own contradictions - in this case, the necessity for risk taking.

We take this notion of a reconstitution of automobility as a starting point. In our study, conducted less than ten years after Fincham's fieldwork, what was striking was the surprisingly widespread acceptance of this reconstitution of the principal object of automobility. It was not only 'marginal cyclists' who espoused it, but almost all participants, whatever mode of transport used. If car driving once provided the illusion of automobility in its promise of autonomous and efficient travel, in accounts from our participants, cycling now unequivocally offered this possibility. One cyclist explicitly described cycling as providing, for him, the seductive freedoms usually evoked in car advertisements:

You're in your four by four and you're driving up this mountain on your own... I feel that when I'm cycling. (Russ, cyclist, 35-44, 'Mixed')

Within inner London in particular, cycling was widely presented as (potentially) providing what Fincham described as 'true automobility', as suggested by Hannah's (typical) claim that cycling meant:

Independence...you don't have to rely on tubes running or buses not breaking down or tube strikes or whatever. You don't have to go anywhere the buses go so, it's flexible, it's transport from your origin to your destination, you don't have to get off and walk or change. (Hannah, cyclist, 18-24, 'White') 
In the city, what the car once symbolised could now be actualised by the bicycle. 'Freedom' was a trope that recurred in cyclists' descriptions of their travel mode. More surprising, perhaps, such imagery also occurred in the imagination of most non-cyclists:

[You'd have] the independence and the freedom to go further and not be restricted by bus routes and walking times. (Hilary, trainee, 35-44, 'White')

[as a cyclist] you are self dependent. In the sense that you not relying totally on the slow moving public transport. And of course you...save the environment. (Li, non-cyclist, 3544 'Asian')

Li's rider on the ecological appeal of cycling is illustrative of the moral discourses that ran through many narratives of travelling London. 'Saving the environment' may not be the primary incentive to cycle, but cycling is 'of course' contributing to the moral ecological work that is assumed to be part of the citizen's responsibility.

\section{'Driving is the new smoking'}

If the bicycle represented at least the seductive possibility of 'true automobility' in London, the car no longer could. Rather than being a default choice, car travel was universally described as not only dysfunctional but as inherently morally dubious. Many from inner London reported simply not driving at all:

I wouldn't consider driving in London, I'm never driving again. I don't have a car - I stopped having one 6 years ago. (Sarah, trainee, 55-64, 'White')

That private motorised transport had once been a normal expectation of mobility in the city is suggested by Teresa, who still owned a car and recalled having learned to drive when she moved to London over thirty years ago because 'it would have been ridiculous to be in London and not drive'. Asked why she now preferred to use the bus, she said: 
A) to save the world! [laughs], B) to save my petrol...you don't know where to park, you get a ticket every time you turn like this [demonstrates], so that's why [laughs]. (Teresa, trainee, 55-64, 'White')

This list of reasons neatly encapsulates the challenges of driving in London, but the initial throwaway joking 'to save the world' is telling. It reflects a normative stance, the expectation that this is the kind of thing we all agree on. Such environmental concerns were commonly referred to in accounting for preferences in transport modes, and usually with similar suggestions that this is the accepted view, that we must all 'consider the environment'. Not surprisingly, cyclists were the most expansive on the environmental benefits of cycling, and on its ability to therefore confer the moral high ground:

To be fair, it does make me feel smug...in the sense that I'm doing something that's not hurting the environment, 'oh I'm so good I'm cycling, I'm being fit and...I'm not going to get fat'. (Julia, cyclist, 25-34, 'White')

I feel like it's a bit of an effort, so I feel like it's something I do which is for my benefit but also for the benefit of the environment...I feel sort of pleased with myself for going to that trouble to do that. (Katrin, cyclist, 25-34, 'White')

However, routine comments from many non-cyclists also suggested broad agreement with a moral consensus that cycling has a status as the most virtuous mode of transport, primarily because it minimised environmental impact. This made cycling a prime candidate transport mode for any 'responsible' traveller:

I think it [cycling] would make a big difference. It would be nicer to think that I'm contributing to cutting down on all the $\mathrm{CO}$ emissions and all the rest of it, and not being the one pumping up loads more into the air. (Carmen, non-cyclist, 35-44, 'Black')

If cycling was at the top of a moral transport hierarchy, car travel clearly occupied the bottom rung. That this hierarchy was assumed to be widely shared was evident in the ways in which Londoners 'defended' their car use in both interviews and informal conversations, assuming that this transport choice now had to be accounted for in some way. Here, for instance, Sushila, in a 
group discussion, reports how she defended her decision to drive to work as being a hard-earned reward for years of difficult public transport commuting:

You know my daughter's very environmental, she's all green, very green, and she labelled me by saying, you know, 'car driving is the new smoking', I said, OK. [Laughter] Exactly, I said, are you telling to somebody who's been taking the bus for two and a half years from all the way to [neighbourhood], and here, I can live with that. I know there are a lot of positive images in the paper about bicyclist people, they seem to be doing the right thing and we're not, I totally understand that, they are doing the right thing, I'm not disputing that, but some of them need to be taught how to drive... (Sushila, non-cyclist, 'Asian')

Sushila's entertaining story of her daughter's disapproval also, though, suggests the instability of this new hierarchy. First, there are still rationales for choosing to drive. Second, although cycling may be inherently more virtuous than driving, cyclists themselves, it seems, are morally ambivalent. Sushila's coupling of moral approval with a complaint about cyclists' behaviour is typical from the non-cyclists in this study (and indeed those reported in other studies (Christmas et al 2010)). Cycling as an idealised mode offers automobility and ecological moral worth, but its practice incurs potential disapproval of inappropriate road use, echoing a normative assumption of car driving. Additionally, cyclists themselves risk appearing sanctimonious:

'I'm cycling because I'm a Greenpeace fanatic' or 'I'm cycling, look at you causing all this pollution'. Do you know what I mean? You sometimes feel there's a little bit of arrogance with some of them...they think that they're perhaps a little bit better than the rest of us. (Grace, trainee, 55-64, 'White')

Apparent remnants of car-based automobility also persisted in the accounts of drivers in outer London, where there are fewer public transport options, and no congestion charge to act as a financial disincentive to driving. Here, some residents and workers still framed the car as a convenient lifestyle necessity: 
I don't have to walk to the bus stop, I don't have to wait for a bus, I don't have to get on the bus full of school kids. I don't get wet in the rain. Just convenience really. Just for personal selfish reasons. (Jennifer, trainee, 55-64, 'White')

We've also often got quite a lot to carry, book bags, gym kit, lunchboxes...then taking them on to other after school activities like swimming and stuff. (Sally, trainee, 35-44, 'White')

However, these appeals to traditional automobility were fragile, and offered apologetically, with Jennifer (above) describing her reasons as 'selfish', and Sally going on to note that:

there's not really any excuse [to drive], to be honest, especially in the summer and it's, sometimes in the summer we do try more to walk. (Sally)

That accounts of the pleasures or necessity of driving require such moral work suggest that, at least in London, the hegemony of a car-dominated 'regime of automobility' has been disrupted. Rather than assuming a normative stance of taken-for-granted car based mobility, our interviewees routinely tempered their accounts of driving with an acknowledgement of this being a potentially morally discrediting choice:

I get to use my car whenever I need to, it's, it just fits around me rather than me having to wait for public transport... [but] well, I do carry a lot of guilt about the environment because that's something that concerns me. (Claudia, non-cyclist, 25-34, 'Black')

In describing how they travelled the city, interviewees therefore evoked not only needs and desires, but also moral responsibilities. The most overt of these were in routine references to environmental obligations, referred to by both cyclists and non-cyclists.

\section{The responsibilities of the travelling body}

Environmental responsibilities to the planet and the city could of course be enacted by simply not driving, rather than actively choosing to cycle, as Lorenzo notes: 
I don't really drive, and...the buses and the tubes are going to run regardless if I'm on it or not, so...I guess [the environment's] not that great of an excuse [to cycle]. (Lorenzo, cyclist, 25-34, 'Mixed')

However, the moral worth of cycling in particular rested on its construction as the ultimate mode for meeting a range of citizenship obligations. In essence, contemporary citizenship required not just the espousal of ecological commitments, but also the enactment of a particular style: that of prudential and knowing agency, with the citizen traveller responsible for transporting themselves around the city in ways that minimised dependence on others, whilst managing personal wellbeing in the most efficient way possible. Responsibility to maintain one's own health was frequently referenced in interviews, and indeed health concerns were an explicit rationale for many transport decisions, with the underground widely disliked for its potential threats to both physical health (through close contact with potentially contaminated others) and mental health (from the stress of crowds). Choosing to catch the bus or walk minimised such risks, providing exercise, in the case of walking, or simply time to relax:

I like walking because...it's a form of exercise and it's a way to unwind for me, I like the time to myself. (Kelly, cyclist, 45-54, 'Black')

However, cycling was cited as the mode that maximized this potential for discharging a responsibility to health and wellbeing: the cycling body is not only demonstrably physically fit, but is visibly engaged in health maintenance. Significantly, by combining exercise with transport, this was also done efficiently.

To enact this level of responsibility and efficiency whilst travelling required a particular style of engagement with transport systems: one that that was widely described as being knowledgeable, alert and assertive. By demonstrating their detailed knowledge of London's spaces and routes, short cuts and interconnections, residents and workers situate themselves as 'belonging to' rather than simply 'being in' the city: claims to knowledge are claims to being 'citizens' rather than those just passing through:

Some places like Covent Garden to Leicester Square, it's only a two minute walk, but people that get on the tube don't know that. (Roisin, trainee, 25-34, 'White') 
To traverse the city as a citizen requires utilising such knowledge in an 'alert' way: by avoiding wandering slowly or hesitantly while consulting a map, for instance, or holding up a bus boarding queue to ask for information. These elements of knowledge and alertness are evoked in many texts on 'how to' travel the city. Transport for London's website (Transport for London 2010), for instance, contains advice encouraging public transport users to be alert and knowing travellers, especially at night: to plan journeys, and to avoid intoxication or headphones which may limit awareness of immediate risks. If the urban citizen in public generally has responsibilities to be knowledgeable, alert and aware, then the cyclist is perhaps the quintessential citizen, for cycling (as it is currently constituted in London) demands such qualities. More detailed knowledge is required than for other modes. First, knowledge of routes is needed: almost all cyclists (however new to cycling) knew precisely how many miles or kilometres their journey each day covered:

[the journey] is five miles...I google mapped it...I found a way which skipped the main roads...in rush hour, you lose a lot of time getting stuck at lights. (Max, trainee, 25-34, 'Mixed')

Few non-cyclists recounted such details. Second, knowledge of the risks of the road are essential: staying safe in motorised traffic, when cycling is still relatively unusual, demands that the cyclist is constantly alert to risk, and assertive in their response to that risk. Assertiveness may be prized by all travelling citizens in the city, but it is constituted as a necessity for cycling in London. In addition to immediate and intimate knowledge of each element of the surrounding road network and its users, assertiveness requires a particular deportment of the physical body/cycling machine which signals to others a 'right' to space on the road. This style, explicitly taught in much cycle training (researcher diary notes), is summarised on the Cycle Training UK website:

Assertive road positioning and behaviour are the key to safe cycling. We teach people to use as much road space as they need to travel safely and effectively. We do not believe that cycle lanes are a requirement for safe cycling. (extract, CTUK 2007) 
It is perhaps most evident in its absence, as suggested in this diary note from a day when many 'unskilled' cyclists were on the road as a result of a public transport strike:

Noticed this morning that many 'tube strike' cyclists don't know what they're doing don't signal, dawdle but still jump lights, cut others up etc. There are long queues on the cycle lane in [Street name] which is frustrating. [Travel diary extract, cyclist)

Only once the assertive deployment of detailed knowledge is accomplished can the cyclist traverse the entire city with relative ease and, in doing so, reveal the limits of other mobilities. In contrast to cycling, the car is then merely an expensive burden; buses and underground trains are limited to their specific routes determined by others; walking restricts the range of the traveller to their immediate neighbourhood.

A final element of contemporary citizenship is that these responsibilities must be discharged as autonomously as possible, with the mobile citizen obliged to travel the city without apparently 'relying on' other people or systems. Again, cycling not only maximises independent travel, it often requires it. The cycling body is essentially a single, bounded, autonomous body. Although possible to cycle alongside companions, or carrying children, most cyclists eulogized their separateness when describing the attractions of transport cycling in the city: the bike could efficiently take you, an individual, wherever you wanted to go, without reference to the desires or needs of others. Indeed 'others' (whether accompanying toddlers, or non-cycling friends or partners), made cycling slightly more problematic:

The problem is that I like to do things with my partner, and she doesn't know how to cycle. So we can't do things together. (Lorenzo, cyclist, 25-34, 'Mixed')

I meet $Y$ to see an exhibition. She is on bike, late because chain fell off on route. Says has locked it by car park - and 'will try not to think about whether it is still there'...After exhibition, we get one beer. Y does not want another, 'not when cycling'. [Travel diary, non-cyclist]

There are opportunities in London to engage in communal cycling spectacles such as the monthly 'Critical Mass' bike ride, and to join leisure cycling clubs. But, those cycling for 
transport overwhelmingly emphasised their independence from other networks, whether those of transport infrastructures or other people.

\section{The contradictions of cycling: autonomy disrupted}

Talk about travel choices therefore implied a number of responsibilities that the urban citizen had beyond those to the planet and the city: to mobilise as knowledgeable, alert and independent individuals. Although these responsibilities could be demonstrated to some extent through other transport choices, cycling demanded them, thus constructing the cyclist as the ultimate moral urban citizen. However, enacting such citizenship is not straightforward. Cycling London safely, as it is currently constituted, requires knowledge, physical skills (balance, some strength and stamina) and the successful adoption of an 'assertive' style. Moreover, despite the discursive construction of cycling as providing the ultimate in autonomous travel, these requirements also must be aligned with a number of complex systems that make possible a particular journey. In practice, cycling required bringing together a particular human body and machine within complex technical and social networks, including roads with more or less cycle-friendly tracks, codes of conduct on highways to minimize vulnerability in motorized traffic, places to safely store the bike and skills to utilise these systems in appropriate ways. Of course, the use of any transport mode also entails co-ordinating such work by the user and others: to become a bus passenger or pedestrian in the city requires 'learning' how to do a range of tasks, from those which may have to be acquired consciously by new users (such as understanding bus routes, or how to obtain the necessary ticket) to more tacit social skills, such as behaving in age and gender appropriate ways in particular parts of the bus or streets. What was unique about cycling, as a relatively unusual modal choice, was that these skills were more 'accountable', in that cyclists and others could reflect on the work needed. Russ, for instance, an experienced cyclist, suggested that to commute regularly by bicycle required not only learning to maintain a bike and repair punctures, but also assembling the 'right' kind of clothes and an ability to discipline the self with 'routines, habits' to manage the logistics needed:

you've got to have things prepared in advance...So that could be anything from ensuring that you've got a rolled and ironed shirt to bring in, suit's here, stuff like that, or whether 
it's even bringing in new towels...There's a whole range of different things that I have to think about before I leave, as well as my gear that I wear to actually cycle in...quite often I bring a lot of stuff here and leave it here, and it seems a bit funny to bring in eight pairs of socks and put them in a locker. (Russ, cyclist, 35-44, 'Mixed')

Non-cyclists and new cyclists were more likely to draw attention to the systems needed to make apparently effortless journeys possible. One alludes to these in her account of her work-mates' routines:

People that cycle come into the office and they must have a shower every day and then you've got the wet towel hanging around or whatever... cyclists are always in a bit of a flap about, oh my God, 'I need to have a shower, I haven't had a shower', or need to get into their cycling gear before they go out. (Jasmine, non-cyclist, 25-34, 'Asian')

Networks also included those of the bicycle itself: a machine that had to be chosen, purchased, understood, and maintained, and which, for new cyclists, could be challenging to align with the physiology and capabilities of the individual human body:

I have done better [in the cycling lesson] than the first week because I was given the wrong bicycle before and the crank was too high for me so by the time I found the pedal I lost my balance. (Teresa, trainee, 55-64, 'White')

[At cycle training session] $\mathrm{M}$ explained that a bike is at the correct height when your leg is straight as your heel is on the pedal positioned at 6 o'clock. The horizontal vs slanted bar issue is related to the length of your torso... [explanation continues] [Fieldnote extract]

Other systems include formal and informal rules through which interaction with other elements of the road network are managed. Breaches in expected behaviour illustrated the instability of these, with uncertainty about how rules are practiced:

because quite often I've stopped at a red light and someone's pulled up and just cycled straight past me and I'm going...do I just look like an idiot now, do I just have 'newbie' across my head? (Max, trainee, 25-34, 'Mixed') 
To cycle autonomously thus involves the co-ordination of a large number of skills, technologies and systems. The technologies of the bike itself and its adaption to the particular human rider, the road system, the rules for using this system, where to place the bike when it is not being ridden, how to clothe the travelling body and then the arrived-body, all have to be brought together with a particular social body: one that is physically fit, alert and knowledgeable. Finally, for cycling to provide 'true automobility' in practice as well as theory, this co-ordination must be rendered invisible. For those who have acquired these skills, the 'systems' could disappear, and the bicycle could be constructed as a kind of mechanical extension to the human user that therefore enhanced their autonomous mobility, as Rachel suggests:

[cycling means] Not dragging a huge great vehicle around with me full of petrol and burning up, you know, not having to pay for parking. Being able to take my bike anywhere, really...It's quicker and easier, isn't it? (Rachel, trainee, 45-54, 'White')

\section{Exclusion and marginal citizenship}

We suggest that in London, the discursive construction of cycling as the most laudable choice for the traveller citizen is rooted in the resonances it has with particular contemporary citizenship responsibilities. However, cycling contains its own contradictions, making these responsibilities, in practice, complicated to enact. To illustrate the tensions in this construction of cycling as citizenship, we turn to one group of Londoners who were not only disenfranchised from cycling, but also from many other transport modes. Their citizenship was, in some ways, rendered marginal (Nash 2009) by this exclusion: limited in terms of physical access to the city in which they lived, they were reminded of their own marginality whenever they tried to traverse the city. The example is from a group of Asian parents who discussed the challenges of travel beyond the local area which could be comfortably walked with accompanying children. Using bicycles to get around was, for them, an absurd suggestion: impractical for long clothing, or carrying children, and considered inappropriate for women in their community (Steinbach et al 2011). However, their exclusion extended to most transport modes, with structural barriers that underlined their marginal urban citizenship in striking ways, as their geographical mobility was restricted by the economic and social organisation of city transport. The parents were in broad 18 
agreement on the problems. Underground trains catered primarily for workers: they were too expensive, and at weekends (when parents were most likely to use them) made inefficient by delays and engineering work. Few women could drive and so, even in households with cars, journeys were determined by the availability of husbands or sons. Buses were more affordable, but experienced as hostile and uncomfortable environments, especially for children, with the threat of racist incidents. Extracts from their discussion illustrate the problems they faced:

F Yeah, I find it [underground] too expensive for myself.

F Yeah, expensive

F Last time I was on it ... it cost me 20 quid for two adults and one child.

F Yeah, [bus number] 17, I would avoid to get on a 17 with my children...there are a couple of experiences that happened in 17, people, doesn't matter if you have a baby and buggy, they'll, no one's going to offer you a seat...they make comments, and do you know, even the bus driver? He wouldn't actually stop the bus and lower his thing in to go in, he's just going to give you an ugly look...and I find it very difficult with young children on a bus, is a bad experience for me.

F [on the bus] 65 you can't get your pram past that pole. ...

M And many of them, many of them [bus drivers], they are racist...If they see you, OK, your face is not white, and green eyes, and

F Behaviour of people in one time, after the seven F Yeah, 7/7 incident

F I obviously have a scarf, and you know...There was one incident... and I was pregnant, there was this man...Because of my scarf, this man comes in, and yes, it was straight after the 7/7. He moved out and he said, "well, at least I'm not a Muslim like her", and that shook, that frightened me so much, never, ever I felt so low in my self esteem.

If citizenship responsibilities can be enacted through transport choices, marginal citizenship could be signalled by such constrained choices. For those on incomes too low to afford the underground, or for whom buses were potentially an arena of racist harassment, cycling is just 
one more unavailable mobility practice. In such cultural contexts, rather than offering an opportunity to display responsible citizenship, cycling is potentially an additional indicator of marginality, as Jasmine suggested in her interview:

I'm a Muslim, [national identity] female, I don't think it's, it would be culturally accepted if I were to [cycle]...people would raise their eyebrows, it would really make me self conscious, people would think I was really tight because I'm probably obviously saving on the pennies, no-one sees it in terms of environmental friendliness or unfriendliness (Jasmine, non-cyclist, 25-34, 'Asian')

Thus, where mobility is materially and structurally constrained, it cannot so easily provide an arena for demonstrating citizenship obligations: and citizenship rights, in consequence, become potentially more eroded.

\section{Discussion}

We have suggested that, in one city at least, the hegemony of car-dominated automobility appears to have fractured significantly, with a new moral economy of transport emerging. Following Fincham (2006), we suggested that within this new moral economy, cycling holds the promise of 'true automobility', but that it has its own contradictions. Although few people actually do cycle in London, we identified a normative discourse of mobility that constituted car travel as a morally dubious choice which had to be defended, and cycling (in principle) as encapsulating 'moral mobility'. Cycling enabled the ultimate 'citizen traveller' to traverse London, demonstrating knowledge of and belonging to the city, and (crucially) ecological commitment to the planet. We suggest the discursive popularity of cycling, despite its relative rarity as practice, in part results from the opportunities it affords for the enactment of citizenship. Accounts of travelling the city suggest that contemporary citizenship in London entails a particular set of responsibilities and rights. The London citizen has a 'right' to the whole city, rather than just their neighbourhood. Cycling enables this right to be literally inscribed, as the individual body/machine traverses the city's streets. Citizens have a responsibility to the self (to participate in the project of body/mind enhancement; to be knowledgeable; to be autonomously 
mobile) but also responsibilities to the collective. Public transport users, drivers and cyclists in this study drew to an unexpected extent on moral discourses relating to the environment to account for transport mode choices. Almost all interviewees spoke of the moral imperative to reduce car use and to 'do your bit' for the environment. These ecological responsibilities were expressed as those both to the city (the local environment of congested and polluted roads) and to the broader, globalised, collective referenced in 'the environment'. If sociologists have characterised car-dominated automobility as a system which normalises and black-boxes the desirability of driving, there is perhaps evidence here that in one location at least, resistance to the regime of automobility is more than marginal. Certainly, the new moral hierarchy appeared to have broad support.

Moving beyond automobility is generally presented as an emancipatory project. At one level, the accounts of London's citizen travellers could be read optimistically, as marking the success of recent policy and scientific discourses of health, climate change and liveable cities. However, if we are taking seriously a critique of automobility (in unpacking its contradictions) we are also obliged to take an equally critical stance on its alternatives. These too have moral effects, and these effects are likely to be differentially distributed across populations. The new regime of transport in the city has its own antagonisms. Emergent discourses of responsibility are not universal, and resonate more closely with some urban identities than others. As Urry (2007: p48) notes, physical travel involves corporeal movement and the interactions of: 'lumpy, fragile, aged, gendered, racialized bodies ...[which] encounter other bodies, objects and the physical world multi-sensorily'. These social and biological bodies were evoked in various accounts of travelling London, and it is clear that some kinds of bodies are more able to become citizen travellers than others. We have suggested that first, the 'autonomous' bicycle is only made possible by the considerable 'work' undertaken to enable cycling to provide independent mobility. What follows is that this work may be less available to some social bodies than others. If car dominated automobility socially disables those who cannot drive - excluding children, for instance, from public space (Freund and Martin 2004) - a cycling dominated mobility regime also potentially has specific effects in specific built environments. In London, with busy streets and fast moving motorised traffic, cycling requires not only particular physical abilities, but (more significantly for many of our respondents) a constant alertness. To dither, or to travel 
aimlessly and deliberately inefficiently, or to travel in large communal groups, or to travel in order to maximize the opportunities for spectacle or interaction were all mobile practices which could not be reconciled easily with cycling as it is currently constituted in this setting. To be communal, one could travel the underground with a group of friends, or with family in the car or bus. To be lazy, or to day dream, one could sit on the bus watching life go by, or dither slowly through London's back streets. Many such bodies do exist in London but they are not so easily constituted as citizen-travellers, in the ways this figure was evoked in the accounts of transport in the city. Citizen-travellers are efficiently moving from one location to another, as prudential agents maximising their contribution to wellbeing, the city and the planet. They do not include non-citizen tourists, taking up space on crowded streets, with pauses to consult maps or shop fronts. Crucially, they do not include those 'marginal citizens' (Nash 2009) whose rights to the whole city are curtailed by the social structural organisation of the transport system, such as the parents quoted above, whose ability to use public transport was constrained by cost and racist exclusion, and for whom cycling was considered inherently inappropriate. The body-bicycle machine envisaged in the idealised version of the automobile cyclist is neither possible nor desirable for all. The gaps between emergent discourses of responsible travelling citizenship and the lived experiences and identities of many Londoners help explain why cycling (despite its seductive status as the archetypal, responsible mode choice for the traveller-citizen) is not (yet) a transport mode choice for many in the capital.

\section{Acknowledgements}

Earlier versions of this article were presented at the BSA Medical Sociology conference and a CRESC workshop, and we are grateful for feedback from conference participants. This research was funded by NHS Camden and Transport for London. We would also like to thank: Phil Edwards and two anonymous referees for helpful comments on the paper; steering committee members Koy Thomson and Suzanne Lutchmun for support and comments on earlier drafts; Gemma Phillips and Kate Nolan for contributions to fieldwork; and all the residents and workers who took the time to talk to us about their transport choices. 


\section{References}

Aldred, R. (2010) “ “On the outside”: constructing cycling citizenship' Social and Cultural Geography 11: 35-52

Beckmann, J. (2001) 'Automobility - a social problem and theoretical concept', Environment and Planning D: Society and Space 19: 593- 607.

Beckmann, J. (2004) 'Mobility and safety', Theory, culture and Society 21: 81-100.

Böhm, S., C. Jones, C. Land, and M. Paterson. (2006) 'Introduction: Impossibilities of automobility', in S. Bohm, C. Jones, C. Land and M. Paterson (eds) Against Automobility, pps 316, Oxford: Blackwell.

Christmas, S., S.Helman, S. Buttress, C. Newman, R. Hutchins. (2010) Cycling safety and sharing the road: qualitative research with cyclists and other road users. London: Department for Transport

CTUK (Cycle Training UK) (2007) ‘Our principles’ URL (consulted March 2011) http://www.cycletraining.co.uk/about_us/our_principles.php\#promotion

Department for Transport (2004) Walking and cycling: an action plan. London: DfT Department for Transport (2007) Cycling Policy: An overview. London: DfT. Department for Transport. (2010). National Travel Survey: 2009. Statistical Release.

Fincham, B. (2006) 'Bicycle messengers and the road to freedom', Bohm, S., Jones, C., Land, C. and Paterson, M. (eds) Against Automobility. Oxford: Blackwell.

Freund, P. and G. Martin. (2004) 'Walking and motoring: fitness and the social organisation of movement', Sociology of Health and Illness 26(3): 273-286.

Green, J. (2009) 'Walk this way': public health and the social organization of walking Social Theory and Health.7: 20-38. 
Higgs, P. (1998) Risk, governmentality and the reconceptualisation of citizenship' in G.Scambler and P. Higgs. (eds) Modernity, medicine and health: medical sociology towards 2000. pp. 176197. London: Routledge

Horton, D., P. Rosen and P. Cox. (2007). Cycling and society. Aldershot: Ashgate.

Isin, E. (2009) 'Citizenship in flux: the figure of the activist citizen' Subjectivity: 29: 367-388

Marinetto, M. (2003) 'Who wants to be an active citizen? The politics and practice of community involvement', Sociology 37: 103-120.

Marshall, T.H. (1950) Citizenship and social class. Cambridge: Cambridge University Press Martin, G.P. (2008) “ “Ordinary people only”: knowledge, representativeness and the publics of public participation in healthcare', Sociology of Health and Illness 30: 35-54.

Mayor of London (2010) Cycling revolution London London: Transport for London McBeth, M. (2009). Gender and Cycling. In G. Letherby and G. Reynolds (Eds.), Gendered Journeys, Mobile Emotions, pp 165-176.Aldershot: Ashgate Publishing Limited.

Nash, K. (2009) 'Between citizenship and human rights', Sociology 43: 1067-1083.

Nettleton, S. (1997) 'Governing the risky self: how to become healthy, wealthy and wise'. In:

Petersen, A. and Bunton, R. (Eds), pp 207-222. Foucault: health and medicine. London: Routledge.

Pucher, J. and R. Buehler (2008) 'Making cycling irresistible: lessons from The Netherlands, Denmark and Germany'. Transport Reviews 28 (4): 495-528

Roche, M. (1995) ‘Citizenship and modernity’ British Journal of Sociology 46: 715-733

Sheller, M. and J. Urry. (2000) 'The city and the car' International Journal of Urban and Regional Research 24: 737-755 
Steinbach, R., J. Green, J. Datta and P. Edwards. (2011) Cycling and the city: a case study of how gendered, ethnic and class identities can shape healthy transport choices Social Science and Medicine 72: 1123-1130

Transport for London (2004) Creating a chain reaction: The London Cycling Action Plan, London: Transport for London.

Transport for London. (2009) Trends in Cycling Levels in London RNPR Traffic Note 9.

Transport for London (2010) Travelling at night URL (consulted March 2011)

http://www.tfl.gov.uk/gettingaround/15284.aspx

Turner, B. (1990) 'Outline of a theory of citizenship' Sociology 24: 189-218

Urry, J. (2004) 'The “system” of automobility' Theory, Culture and Society 21: 25-39

Urry, J. (2007) Mobilities. Cambridge: Polity Press

'Indeed Cycling England, the body set up to advise on the promotion of cycling, was abolished in April 2011.

ii These were six English towns who received funds to increase levels of cycling, with some evidence of effectiveness: see http://www.dft.gov.uk/cyclingengland/cycling-cities-towns/results/ (last accessed April 2011)

iii Recruitment was from three boroughs, two in inner London (Camden and Hackney) ( $\mathrm{N}=48$ ) and one in outer London (Richmond) ( $\mathrm{N}=30)$, selected to include settings with contrasting transport infrastructures.

iv Participants were asked to tick one of the UK census categories or describe their own ethnicity. 